\title{
The Konno aortoventriculoplasty after the Bentall procedure
}

\author{
Yuki Nakamura, MD, ${ }^{\mathrm{a}}$ Osamah Aldoss, MD, ${ }^{\mathrm{b}}$ and Marco Ricci, MD, ${ }^{\mathrm{a}}$ Iowa City, Iowa
}

\author{
From the Divisions of ${ }^{\mathrm{a}}$ Pediatric Cardiothoracic Surgery and ${ }^{\mathrm{b}}$ Pediatric Cardiology, University of Iowa Hospitals \\ and Clinics, Iowa City, Iowa. \\ Disclosures: Authors have nothing to disclose with regard to commercial support. \\ Received for publication Jan 15, 2019; revisions received Feb 20, 2019; accepted for publication March 8, 2019; \\ available ahead of print April 20, 2019. \\ Address for reprints: Yuki Nakamura, MD, Division of Pediatric Cardiothoracic Surgery, University of Iowa Hos- \\ pitals and Clinics, 200 Hawkins Drive, Iowa City, IA 52242 (E-mail: yuki-nakamura@uiowa.edu). \\ J Thorac Cardiovasc Surg 2019;158:e49-50 \\ 0022-5223/\$36.00 \\ Copyright (C) 2019 by The American Association for Thoracic Surgery \\ https://doi.org/10.1016/j.jtcvs.2019.03.025
}

Video clip is available online.

The Bentall procedure ${ }^{1}$ is rarely performed in pediatric patients, with exceptions such as connective tissue disorder. We report a young adult patient presenting prosthesispatient mismatch after the Bentall procedure.

\section{CLINICAL SUMMARY}

The patient was a 27-year-old man who had undergone 3 cardiac operations: aortic valvotomy at 8 weeks, homograft aortic root replacement for aortic regurgitation at 10 years, and the Bentall procedure using a $21-\mathrm{mm}$ mechanical valve for the homograft failure at 17 years. His body surface area at the Bentall operation was $1.51 \mathrm{~m}^{2}$. Both coronary arteries were implanted using the button technique at that time. A transthoracic echocardiogram just after the Bentall operation showed a mean gradient across the aortic prosthesis of $29 \mathrm{~mm} \mathrm{Hg}$, Doppler velocity index (DVI) of 0.6, and left ventricular ejection fraction (LVEF) of $61 \%$. Eight years later, his body surface area increased to $1.64 \mathrm{~m}^{2}$. An echocardiogram revealed a mean gradient of $36 \mathrm{~mm} \mathrm{Hg}$, DVI of 0.22 , and LVEF of $57 \%$. He denied any symptoms. Seven months later, he started to feel increased fatigue and shortness of breath. An echocardiogram showed an LVEF of $33 \%$, a mean gradient of $14 \mathrm{~mm} \mathrm{Hg}$, a DVI of 0.29 , and an indexed effective orifice area of $0.57 \mathrm{~cm}^{2} / \mathrm{m}^{2}$. A coronary angiogram showed complete occlusion of the proximal left circumflex artery. Cinefluoroscopy demonstrated normal prosthesis leaflet movement. A magnetic resonance imaging study showed a transmural scar without any viable myocardium in the left circumflex artery territory. Surgery was planned.

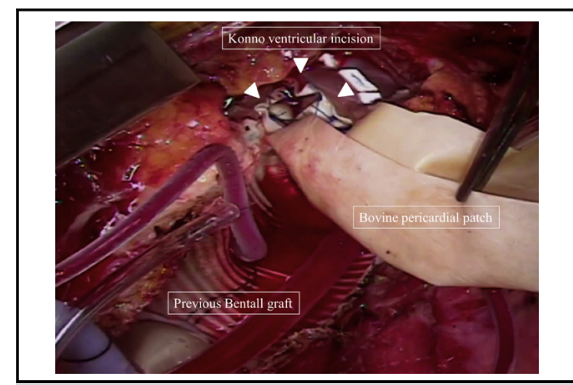

Surgical view of the Konno procedure without taking down the previous Bentall graft.

\section{Central Message}

Aortic valve re-replacement with the Konno procedure without taking down a previous Bentall graft is a useful tool in pediatric and young adult patients who require upsizing of the previous prosthesis.

See Commentary on page e51.
The previous Bentall graft was adherent to the sternum. The patient was placed on cardiopulmonary bypass via femoral-femoral cannulation, and cooling was initiated. The right carotid artery was exposed, and an 8-mm Dacron graft was connected in an end-to-side fashion. An additional cannula was placed in the graft to establish selective cerebral perfusion. At a temperature of $18^{\circ} \mathrm{C}$ under selective cerebral perfusion of $10 \mathrm{~mL} / \mathrm{kg}$, resternotomy was completed. The superior half of the Bentall graft was longitudinally opened simultaneously with the resternotomy because of the adhesion. Lower-body perfusion was resumed through the femoral artery cannula with a Foley catheter placed into the descending thoracic aorta. Selective antegrade cardioplegia was delivered. The previous prosthetic valve was excised. The incision of the Bentall graft was extended down into the ventricular septum. The right ventricular free wall was also incised. A bovine pericardial patch was secured to the edges of the ventricular incision (Figure 1). A 25-mm On-X (On-X Life Technologies Inc, Austin, Tex) aortic valve was placed with interrupted pledgeted sutures. The same patch was used to augment the Bentall graft up to the native aorta. Another bovine pericardial patch was used to reconstruct the right ventricle free wall. Convalescence was good, and the patient was discharged on postoperative day 9. An echocardiogram before discharge revealed 


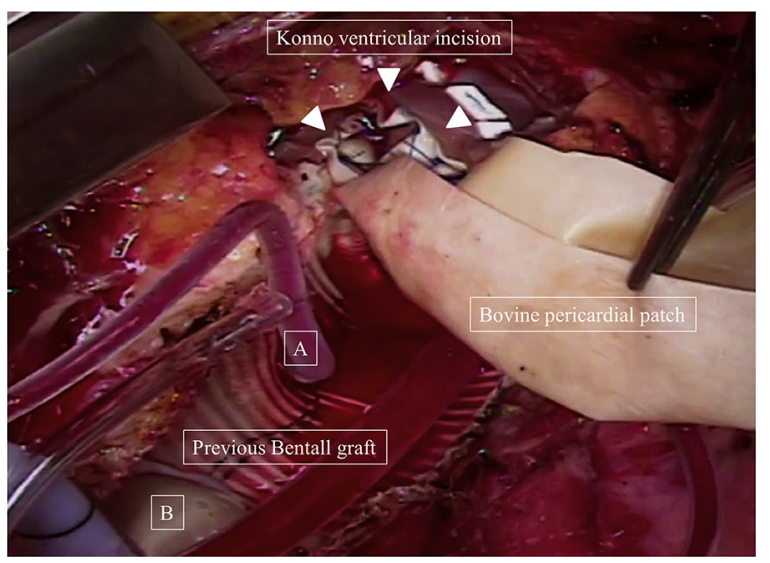

FIGURE 1. Surgical view of the Konno procedure without taking down the previous Bentall graft. A bovine pericardial patch was secured to the edges of the ventricular incision (white arrow). A, Catheter in the left coronary artery button to deliver selective antegrade cardioplegia. B, Foley catheter that was placed into the descending thoracic aorta.

a mean gradient of $6 \mathrm{~mm} \mathrm{Hg}$, no paravalvular leak, and LVEF of $56 \%$. Video 1 shows the procedure.

\section{DISCUSSION}

Reoperative aortic root replacement is related with an operative mortality of $14.3 \%$ even in the current era at a high-volume center. ${ }^{2}$ In their cohort, $14.2 \%$ of the patients required coronary artery bypass grafting for noncoronary artery disease. ${ }^{2}$ This suggests difficulties with reimplantation of the coronary arteries in the setting of reoperative aortic root replacement with previous root replacement. ${ }^{3}$ Our patient had complete occlusion of the left circumflex artery and the left ventricle dysfunction preoperatively; therefore, it was prudent to avoid manipulating the coronary arteries. Reoperative aortic valve replacement in a previous biologic Bentall graft without taking down the graft was described in a small case series, which should be beneficial to avoid mobilizing the coronary buttons and dissection of the aortic root, thereby decreasing the risk of intraoperative bleeding. ${ }^{4}$

Upsizing the previous prosthesis was necessary in our patient because of prosthesis-patient mismatch. The Konno aortoventriculoplasty $^{5}$ rather than posterior annular enlargement was adopted to avoid dissecting dense

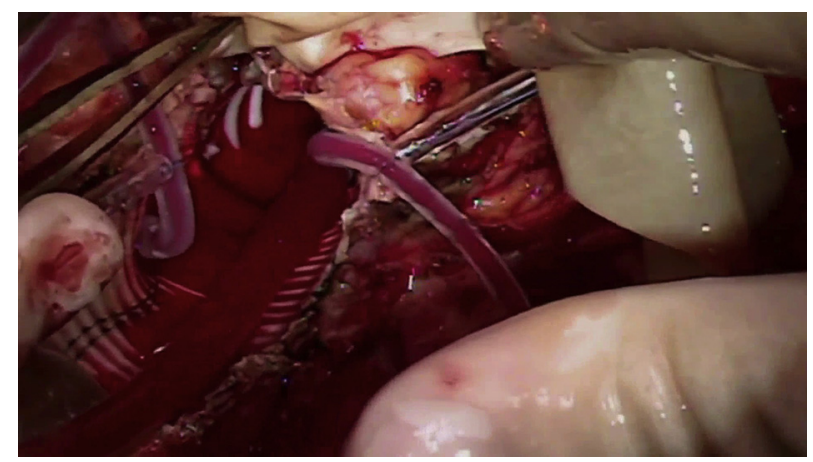

VIDEO 1. The Konno procedure without taking down the previous Bentall graft. Preoperative echocardiogram, coronary angiogram, intraoperative recording, and postoperative echocardiogram are shown. Video available at: https://www.jtcvs.org/article/S0022-5223(19)30695-6/fulltext.

adhesions around the aortic root. A mean gradient of $29 \mathrm{~mm} \mathrm{Hg}$ just after the last Bentall operation suggests that a larger prosthesis might have been necessary at that time. However, the mean gradient further increased in the last 8 years despite the absence of thrombus and pannus formation, reflecting the patient's somatic growth. Pediatric cardiac surgeons may encounter reoperations after aortic root replacement in which larger aortic prosthesis is necessary or left ventricular outflow tract obstruction has to be addressed because of growth potential and recurrent left ventricular outflow tract obstruction that are inherent in pediatric patients. This approach is a useful armamentarium for pediatric cardiac surgeons who are familiar with the Konno procedure.

\section{References}

1. Bentall H, De Bono A. A technique for complete replacement of the ascending aorta. Thorax. 1968;23:338-9.

2. Esaki J, Leshnower BG, Binongo JN, Lasanajak Y, McPherson L, Thourani VH, et al. Reoperative aortic root replacement: outcome in a contemporary series. $J$ Thorac Cardiovasc Surg. 2017; 154:800-8.

3. Schäfers HJ. Reoperative root replacement: to do or not to do. J Thorac Cardiovasc Surg. 2017;154:809.

4. Lau C, Gaudino M, Mazza A, Munjal M, Girardi LN. Reoperative aortic valve replacement in a previous biologic composite valve graft. Ann Thorac Surg. 2016;102:477-80.

5. Konno S, Imai Y, Iida Y, Nakajima M, Tatsuno K. A new method for prosthetic valve replacement in congenital aortic stenosis associated with hypoplasia of the aortic valve ring. J Thorac Cardiovasc Surg. 1975;70:909-17. 